\title{
SHADE TOLERANCE RANKINGS OF RAIN FOREST TREE SEEDLINGS, SOUTHWEST OF SRILANKA
}

BY

\author{
P. A. K. A. K. PANDITHARATHNA
}




\section{DECLARATION}

The work described in this thesis was carried out by me under the supervision of Dr B M P Singhakumara and Prof P M S Ashton and a report on this has not been submitted in whole or in part to any University for another Degree/Diploma.

Panditharathug\%

$24 \cdot 12 \cdot 2004$

P A K A K Panditharathna

Date
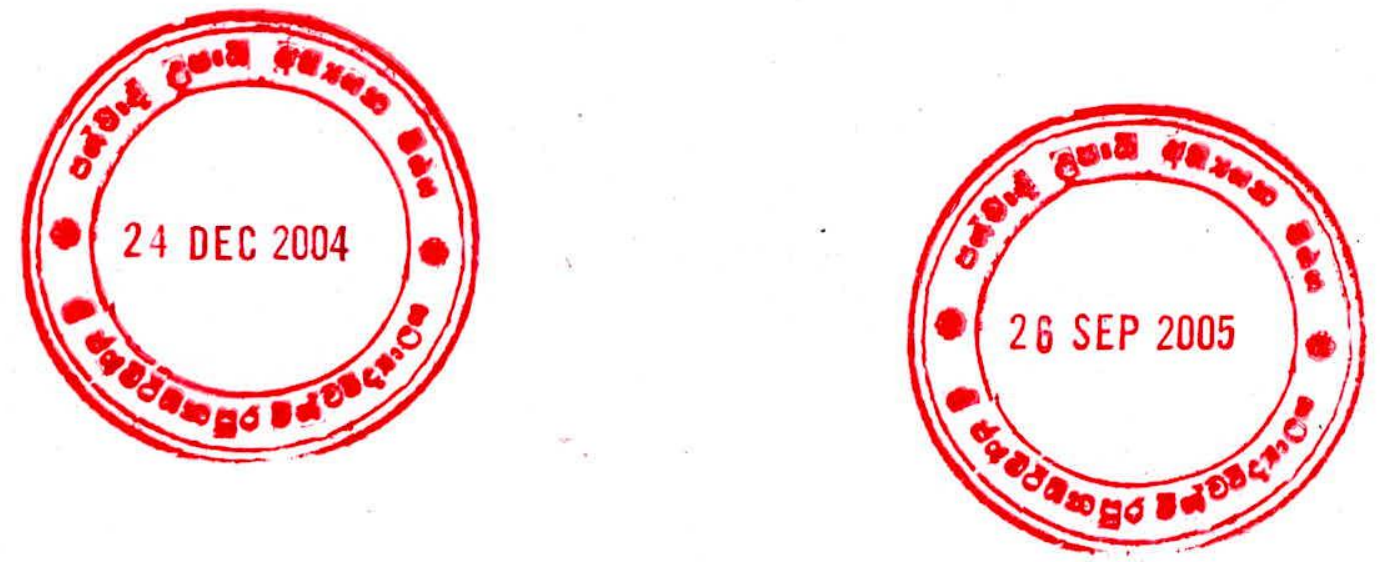
We certify that the statement made by the candidate is true and that this thesis is suitable for submission to the University for the purpose of evaluation.

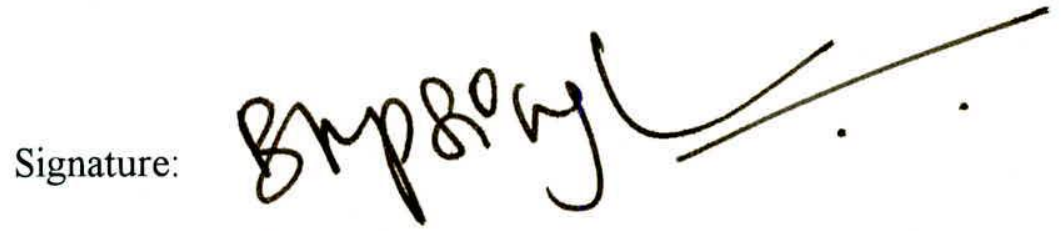

Internal Supervisor: Dr B M P Singhakumara, D.Phil. (Oxon.)

Head, Department of Forestry \& Environmental Science,

University of Sri Jayewardenepura,

Nugegoda,

Sri Lanka.

Date: 23 Sept. 2005

Signatuke:

External Supervisor: Prof P M S Ashton

Professor of Silviculture and Forest Ecology, Director of School Forests,

School of Forestry \& Environmental Studies, Yale University, USA.

Date: 


\title{
SHADE TOLERANCE RANKINGS OF RAIN FOREST TREE SEEDLINGS, SOUTHWEST OF SRI LANKA
}

\author{
BY \\ P. A. K. A. K PANDITHARATHNA
}

Thesis submitted to the University of Sri Jayewardenepura for the award of the Degree of Doctor of Philosophy in Forestry on Tropical Forest Ecology. 


\section{TABLE OF CONTENTS}

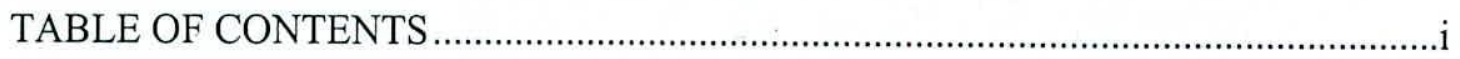

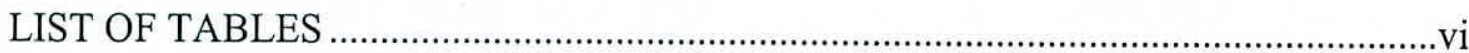

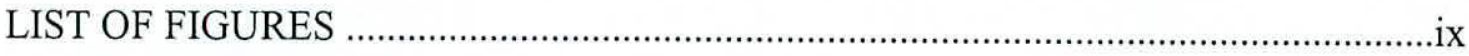

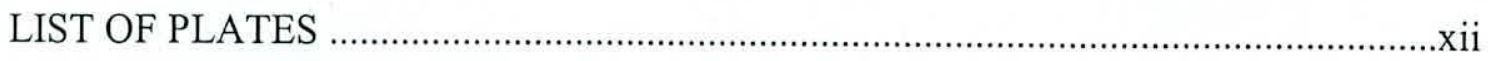

ACKNOWLEDGEMENTS ....................................................................................ii

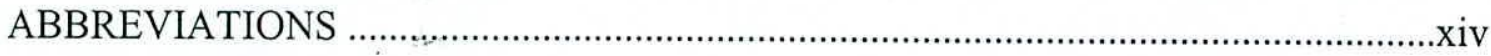

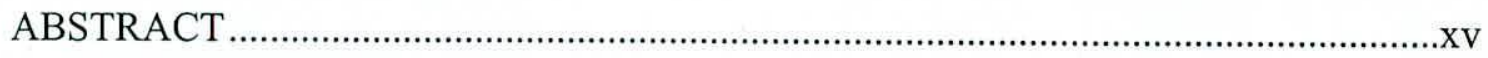

CHAPTER 1: INTRODUCTION …………………………………………………. 1

1.1 General Introduction and Objectives ............................................... 2

CHAPTER 2: LITERATURE REVIEW ……………………………………..... 9

2.1 Rain forests in south west Sri Lanka.................................................10

2.1.1 Shade tolerance of rain forest trees .........................................10

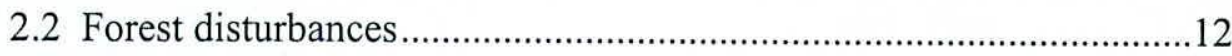

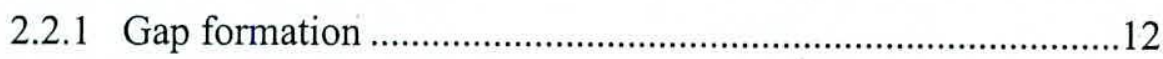

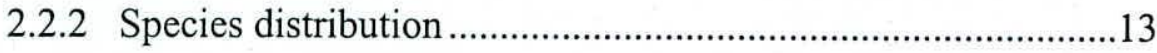

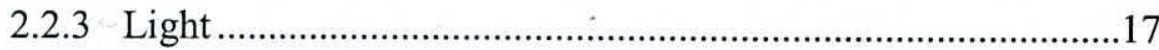

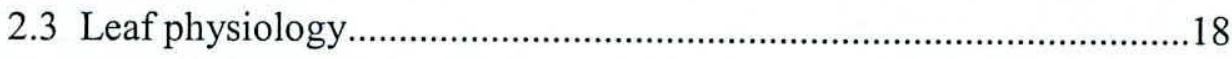

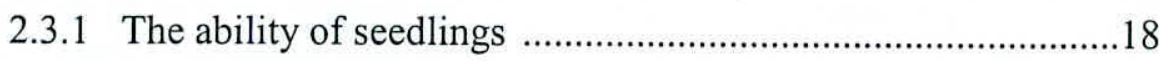

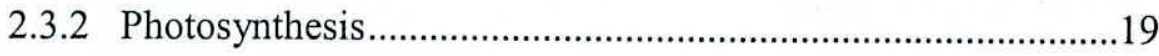

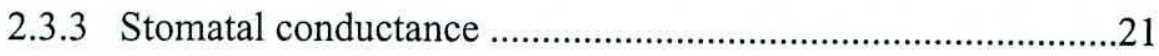

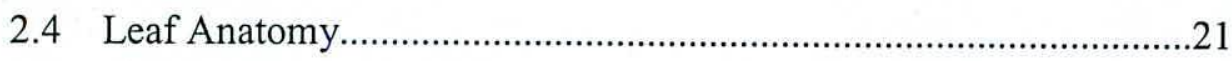

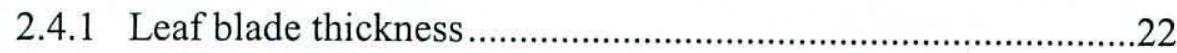




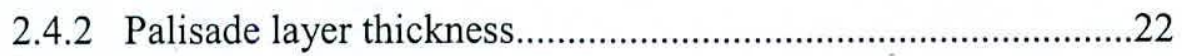

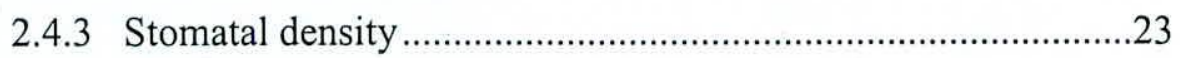

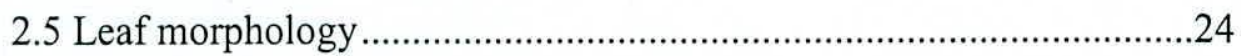

2.5.1 Leaf area and weight ........................................................24

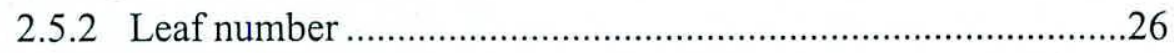

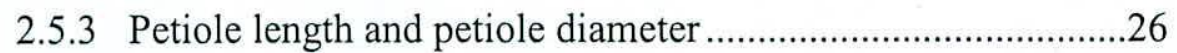

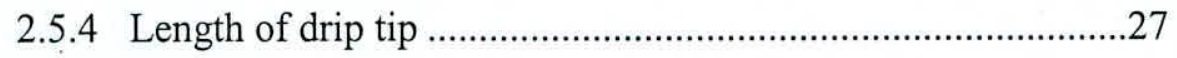

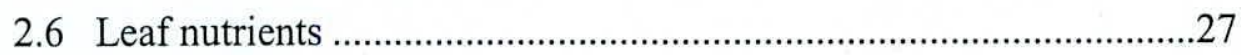

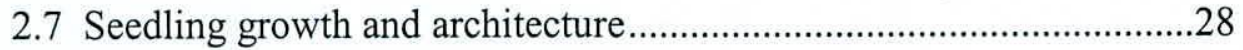

2.7.1 Height and dry mass ...........................................................30

2.7.2 Sun and shade leaves ...........................................................30

2.8 Controlled experiment shelters ................................................... 31

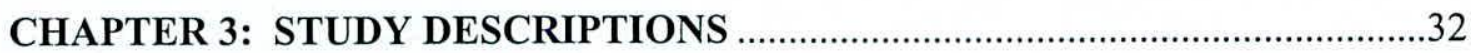

3.1 Study objective and hypotheses ...................................................33

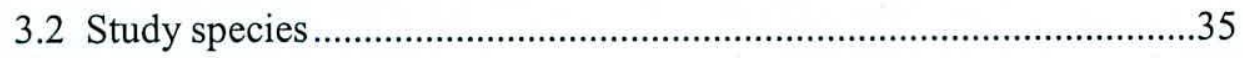

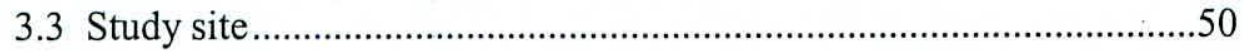

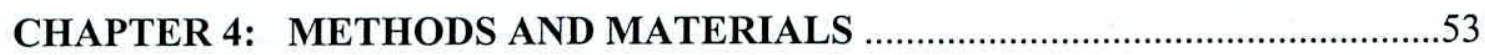

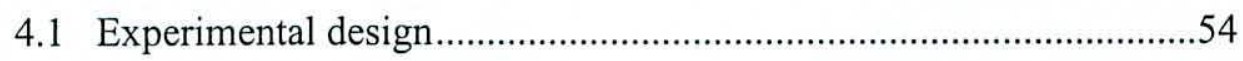

4.1.1 Design of the shelters .....................................................54

4.1.2 Seedling establishment in the shelters................................55

4.1.3 Ambient light in the shelters ..........................................56

4.2 Leaf Physiological experiment....................................................57 


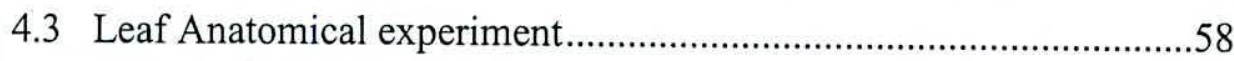

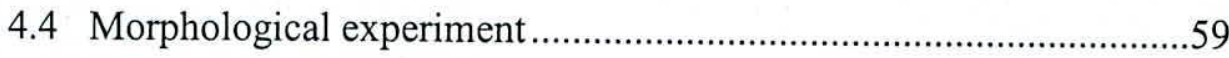

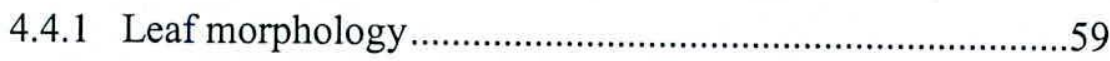

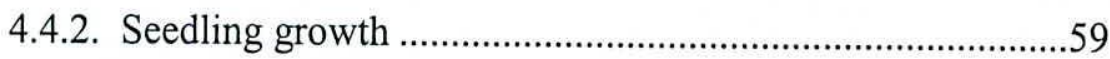

4.4.2.1 Above ground measurements........................59

4.4.2.2 Dry mass allocation.......................................60

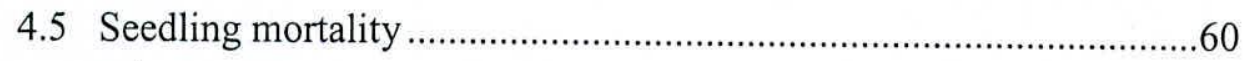

4.6 Leaf display angles and branch architecture ..................................61

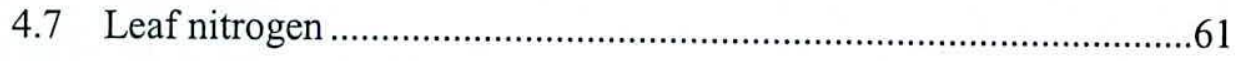

4.7.1 Leaf sampling.............................................................61

4.7.2 Digestion .....................................................................6

4.7.3 Distillation....................................................................62

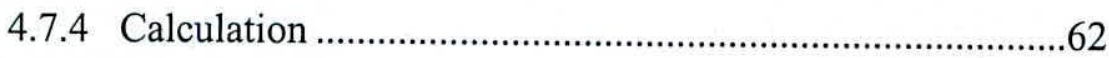

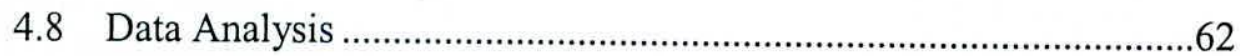

4.8.1 Leaf physiology.............................................................62

4.8.2 Leaf Anatomy................................................................63

4.8.3 Leaf Morphology ….......................................................63

CHAPTER 5: LEAF PHYSIOLOGY RESULTS ....................................................6

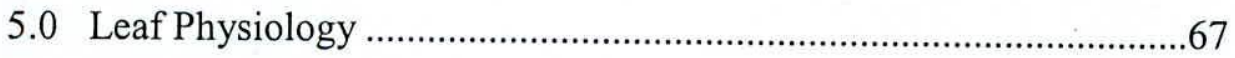

5.1 Photosynthesis...................................................................67

5.2 Stomatal conductance......................................................... 78

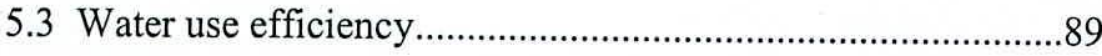


6.0 Leaf Anatomy.......................................................................98

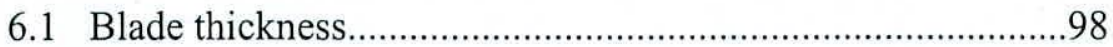

6.2 Palisade layer thickness.......................................................107

6.3 Upper epidermal layer thickness ....................................115

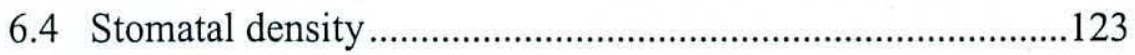

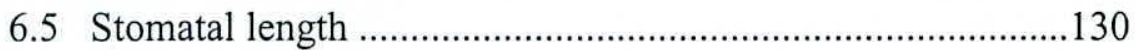

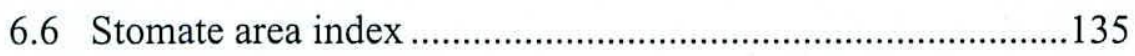

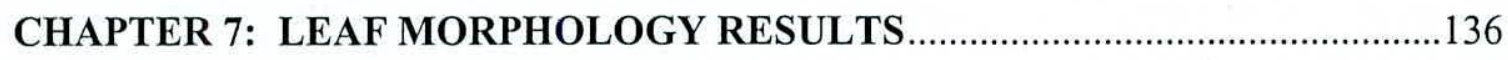

$7.0 \quad$ Leaf Morphology …......................................................................137

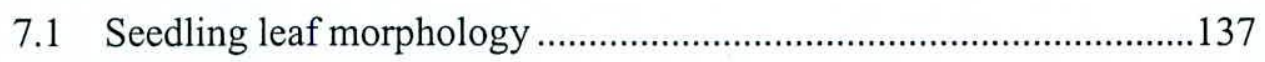

7.1.1 Leaf area and mass .........................................................137

7.1.2 Specific leaf area ....................................................... 14

7.1.3 Margin length ..................................................................143

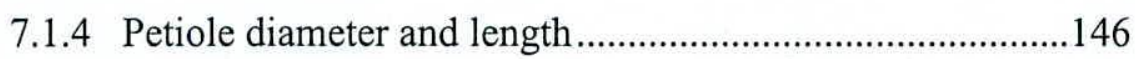

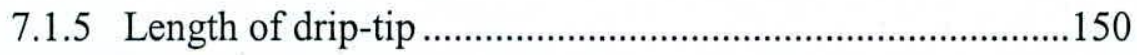

7.2 Seedling Growth performance and Architecture ...........................152

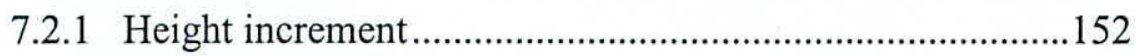

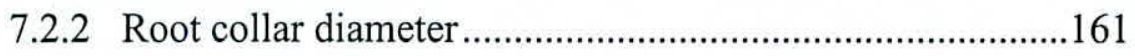

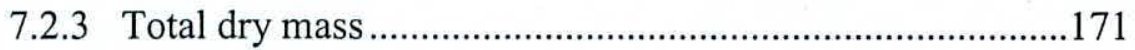

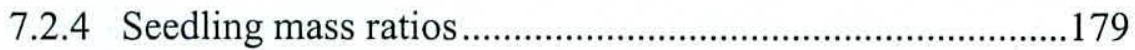

7.2.5 Shoot-root ratio ..........................................................204

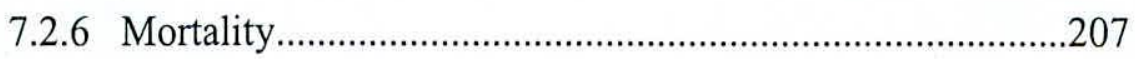




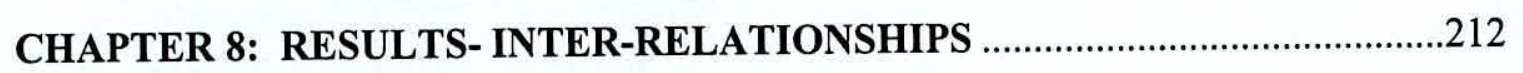

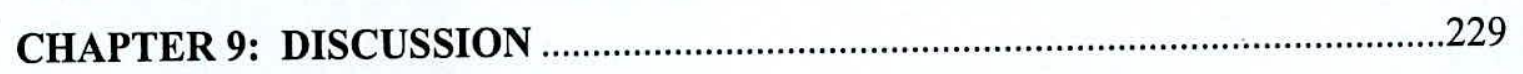

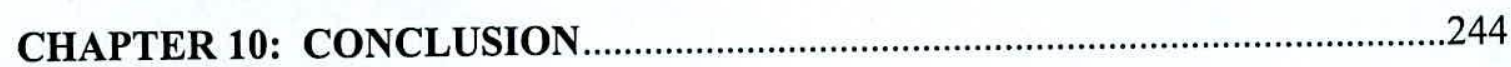

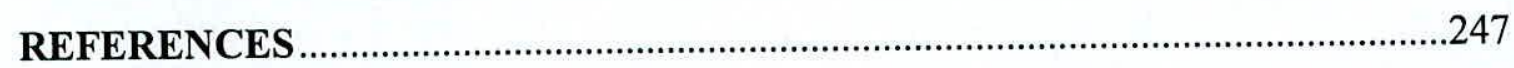

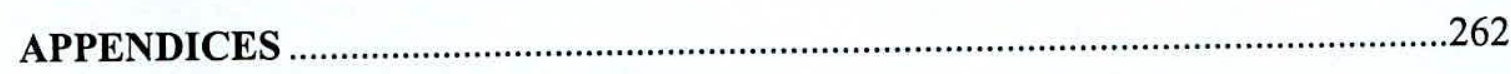

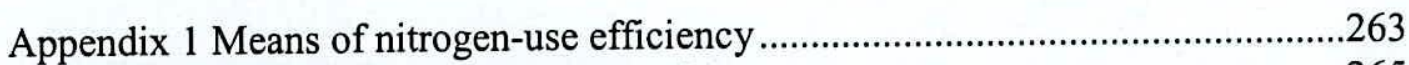

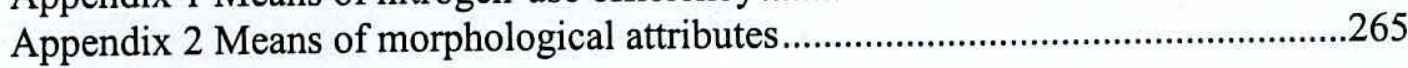

Appendix 3 Photographs 


\section{LIST OF TABLES}

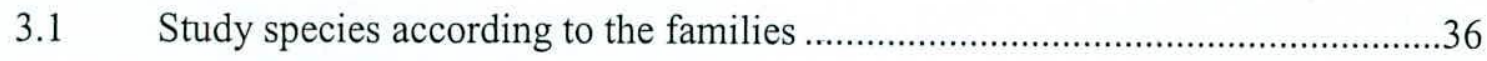

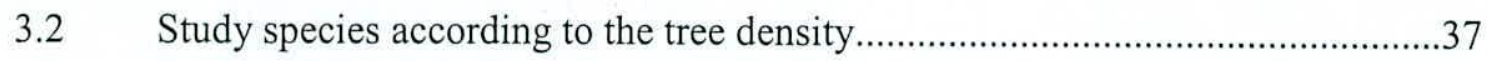

3.3 Anatomical and ecological characteristics of study species ................................39

5.1.1 Means of ambient photosynthesis for canopy, understorey, canopy topographic-restricted and canopy topographic-generalists

5.1.2 Means of maximum photosynthesis among genera of canopy topographicrestricted and canopy topographic-generalists

5.1.3 Means of maximum photosynthesis among multi species genera and, ambient and maximum photosynthesis of 43 species.

5.2.1 Means of stomatal conductance for canopy, understorey, canopy

topographic-restricted and canopy topographic-generalists

5.2.2 Means of maximum stomatal conductance among genera of canopy topographic-restricted and canopy topographic-generalists

5.2.3 Means of stomatal conductance among multi species genera and, ambient and maximum photosynthesis of 43 species

5.3.1.1 Means of water-use efficiency (ratio between Amax and K)

5.3.1.2 Means of water-use efficiency (ratio between Amax and T)

5.3.2 Means of water use efficiency among genera of canopy topographic

-restricted and canopy topographic-generalists

5.3.3 Means of water-use efficiency for 43 species 96

6.1.1 Means of blade thickness for canopy, understorey, canopy topographic-restricted and canopy topographic-generalists.

6.1.2 Means of blade thickness among genera of canopy topographic -restricted and canopy topographic-generalists

6.1.3 Means of blade thickness among multi species genera of canopy topographic-restricted and canopy topographic-generalists... 
6.2.1 Means of palisade layer thickness for canopy, understorey, canopy topographic-restricted and canopy topographic-generalists.

6.2.2 Means of palisade layer thickness among genera of canopy topographic -restricted and canopy topographic-generalists.

6.2.3 Means of palisade layer thickness among multi species genera of canopy topographic-restricted and canopy topographic-generalists.

6.3.1 Means of upper epidermal layer thickness for canopy, understorey, canopy topographic-restricted and canopy topographic-generalists

6.3.2 Means of upper epidermal layer thickness among genera of canopy topographic-restricted and canopy topographic-generalists.

6.3.3 Means of upper epidermal layer thickness among multi species genera of canopy topographic-restricted and canopy topographic-generalists.

6.4.1 Means of stomatal density between sun and shade for multi species genera ......125

6.4.2 Means of stomatal density among species within the same genus

6.5.1 Means of stomatal length between full-sun and deep-shade for multi species genera

6.5.2 Means of stomatal length among species within the same genus.

7.1.1.1 Means of single leaf area for canopy, understorey, canopy topographic-restricted and canopy topographic-generalists.

7.1.1.2 Means of single leaf mass for canopy, understorey, canopy topographic-restricted and canopy topographic-generalists

7.1.2 Means of specific leaf area for canopy, understorey, canopy topographic-restricted and canopy topographic-generalists

7.1.3 Means of margin length for canopy, understorey, canopy topographic-restricted and canopy topographic-generalists

7.1.4.1 Means of petiole diameter for canopy, understorey, canopy topographic-restricted and canopy topographic-generalists

7.1.4.2 Means of petiole length for canopy, understorey, canopy topographic-restricted and canopy topographic-generalists 
7.1.5 Means of length of drip-tip for canopy, understorey, canopy topographic-restricted and canopy topographic-generalists.

7.2.1.1 Means of height increment values for canopy, understorey, canopy topographic-restricted and canopy topographic-generalists.

7.2:1.2 Means of height increment among genera of canopy topographic-restricted and canopy topographic-generalists.

7.2.1.3 Means of height increment for 43 species 156

7.2.2.1 Means of root collar diameter values for canopy, understorey, canopy topographic-restricted and canopy topographic-generalists

7.2.2.2 Means of root collar diameter among genera of canopy topographic-restricted and canopy topographic-generalists.

7.2.2.3 Means of root collar diameter for 43 species

7.2.3.1 Means of total dry mass values for canopy, understorey, canopy topographic-restricted and canopy topographic-generalists

7.2.3.2 Means of total dry mass among genera of canopy topographic-restricted and canopy topographic-generalists

7.2.3.3 Means of total dry mass for 43 species .174

7.2.4.1 Means of seedling mass ratios for canopy, understorey, canopy topographic-restricted and canopy topographic-generalists

7.2.4.2 Means of seedling mass ratios among genera of canopy topographic-restricted and canopy topographic-generalists

7.2.4.3 Means of mass ratios for 43 species 188

7.2.5.1 Means of shoot root ratios for canopy, understorey, canopy topographic-restricted and canopy topographic-generalists 205

7.2.5.2 Means of shoot root ratios among genera of canopy topographic-restricted and canopy topographic-generalists. .206

7.2.6 Means of arcsine of mortality for 43 species .208

7.2.7.1 Means of nitrogen use efficiency for canopy, understorey, canopy topographic-restricted and canopy topographic-generalists 


\section{LIST OF FIGURES}

5.1.1 Means of photosynthesis between canopy, and understorey

5.2.1 Means of stomatal conductance between canopy, and

understorey

5.3.1 Means of water-use efficiency between canopy and understorey

6.1.1 Leaf blade thickness between canopy and understorey

species

6.2.1 Leaf palisade layer thickness of seedlings between canopy and understorey species

6.3.1 Leaf upper epidermal thickness of seedlings between canopy and understorey species

6.4.1 Means of stomatal density within and between canopy and understorey species

6.5.1 Means of stomatal length within and between canopy and understorey species

8.1.1 Relationship between photosynthesis and stomatal conductance in canopy species

8.1.2 Relationship between photosynthesis and stomatal conductance in understorey species

8.1.3 Relationship between photosynthesis and stomatal conductance in canopy topographic-generalist species

8.1.4 Relationship between photosynthesis and stomatal conductance in canopy topographic-restricted species.

8.1.5 Relationship between photosynthesis and percentage nitrogen in canopy species

8.1.6 Relationship between photosynthesis and percentage nitrogen in understorey species 
8.1.7 Relationship between photosynthesis and percentage nitrogen in canopy topographic-restricted species

8.1.8 Relationship between photosynthesis and specific leaf area in canopy species

8.1.9 Relationship between photosynthesis and specific leaf area in canopy topographic-restricted species

8.2.1 Relationship between total dry mass and root collar diameter in understorey species

8.2.2 Relationship between total dry mass and root collar diameter in canopy species

8.2.3 Relationship between total dry mass and root collar diameter in canopy topographic-restricted species

8.2.4 Relationship between total dry mass and root collar diameter in canopy topographic-generalist species

8.2.5 Relationship between root mass ratio and leaf mass ratio in canopy species

8.2.6 Relationship between root mass ratio and leaf mass ratio in understorey species.....

8.2.7 Relationship between root mass ratio and leaf mass ratio in canopy topographic-generalist species

8.2.8 Relationship between root mass ratio and leaf mass ratio in canopy topographic-restricted species

8.2.9 Relationship between height increment and total dry mass in canopy species

8.2.10 Relationship between height increment and total dry mass in canopy topographic-restricted species

8.2.11 Relationship between height increment and total dry mass in canopy topographic-generalist species

8.2.12 Relationship between specific leaf area and percentage nitrogen in canopy species 
8.3.1 Relationship between blade thickness and specific leaf area in canopy species.

8.3.2 Relationship between blade thickness and total palisade layer thickness in canopy species.

8.3.3 Relationship between blade thickness and total palisade layer thickness in understorey species

8.3.4 Relationship between blade thickness and upper epidermal layer thickness in understorey species.

8.3.5 Relationship between specific leaf area and palisade layer thickness in canopy species 


\section{LIST OF PLATES}

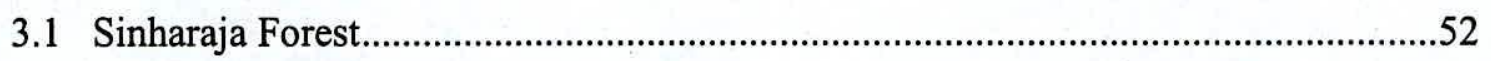

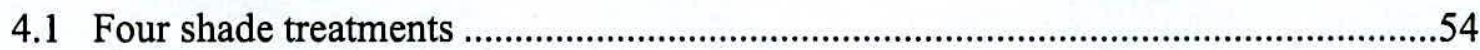

4.2 Seedling establishment in the full sun-shelter..................................................56 


\section{ACKNOWLEDGEMENTS}

Firstly I would like to express my deepest gratitude to my supervisors, Dr. B M P Singhakumara, Head, Department of Forestry and Environmental Science, University of Sri Jayewardenepura, and Prof. P M S Ashton, Professor of Silviculture and Forest Ecology, School of Forestry and Environmental Studies, Yale University, USA, for valuable advice, guidance, kind encouragement, and stress free environment created throughout the research project. I duly appreciate their contribution so willingly given towards the final output in spite of their heavy workload.

I wish to thank Prof (Mrs) D M S H K Ranasinghe, Former Head of the Department of Forestry and Environment Science, University of Sri Jayewardenepura, for allowing the use of laboratory facilities and also to Dr H S Amarasekara, Senior Lecturer, Department of Forestry and Environmental Science, University of Sri Jayewardenepura, for his kind advise, and all academic staff.

I wish to extend thanks to Mr P Dias, Senior Lecturer, Department of Statistics and Computer Science, University of Sri Jayewardenepura, for giving the support in statistical analysis. I must thank Dr. Keerthi Mohotti and his staff, Nematology Division, Tea Research Institute, Thalawakele for giving the help in taking photographs of leaf sections. I acknowledge Dr. H. Gamage and Mr Sisira Ediriweera, for their support.

I would like to thank Mr I D Wijesingha, and Mr S Wettasingha, Technicians, Department of Forestry and Environmental Science, and all the other non-academic staff. I thank Mr R Chaminda Kumara and Mr B W Gunasoma for their field assistance. I acknowledge National Science Foundation and Mac Arthur Foundation funded for the study. Finally I am grateful to all who gave their support willingly to complete this work. 


\section{ABBREVIATIONS}

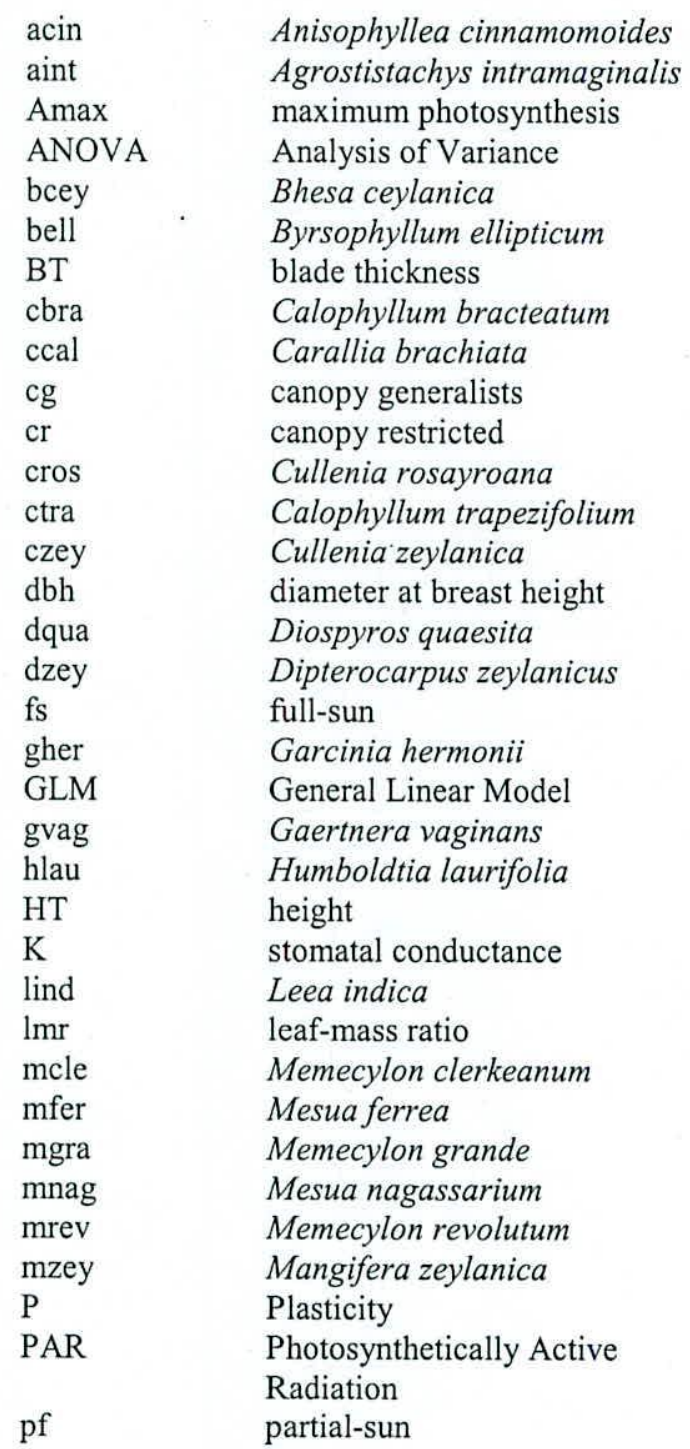

Pn

pnig

PPFD

ppet

ps

pthw

R: FR

$\mathrm{rmr}$

$\mathrm{RCD}$

saff

scas

$\operatorname{scoc}$

scon

scor

sdis

sfir

sgar

sh

SLA

smak

smeg

snee

sope

srub

ssti

stra

swor

szey

$\mathrm{T}$

TDM

TPL

uapi

UE

valt
Photosynthetic rate

Psychotria nigra

Photosynthetic Photon Flux

Density

Palaquium petiolare

partial-shade

Palaquium thwaitesii

Red Far-Red ratio

root mass ratio

Root collar diameter

Shorea affinis

Schumacheria castaneifolia

Symplocos cochinchinensis

Shorea congestiflora

Shorea cordifolia

Shorea disticha

Syzygium firmum

Shorea gardneri

deep-shade

Specific leaf area

Syzygium makul

Shorea megistophylla

Syzygium neesianum

Syzygium operculatum

Syzygium rubicundum

Shorea stipularis

Shorea trapezifolia

Shorea worthingtoni

Shorea zeylanica

Transpiration

Total dry mass

Total palisade layer

Urandra apicalis

Upper epidermis layer

Vitex altissima 


\section{SHADE TOLERANCE RANKINGS OF RAIN FOREST TREE SEEDLINGS, SOUTHWEST OF SRILANKA}

\section{P. A. K. A. K. Panditharathna}

\section{$\underline{\text { ABSTRACT }}$}

The tropical rain forest is considered a mosaic of patches in different stand development stages. It is necessary to know the nature of the light environments, in order to evaluate the responses of seedlings of species to a range of shade conditions. The present study examined forty-three species of eighteen tree families that exist in rain forest of southwest Sri Lanka. Species comprise canopy, sub canopy or understorey trees characterized as late successional and pioneer species, which are either site restricted or generalist species. Experiments were designed to investigate seedling performance of these species grown for two years within shade houses. Leaf morphological, physiological and anatomical attributes were measured in four different shade treatments (full-sun, partial-sun, partialshade, deep-shade).

Results indicated that leaf physiological, anatomical, and morphological characteristics can be used to determine shade tolerance of a species. Canopy species had greater plasticity values of photosynthesis, stomatal conductance, specific leaf area, height increment, root collar diameter, total dry mass, leaf-mass ratio, and nitrogen-use efficiency than understorey species. Canopy topographic-generalists had greater plasticity values to changes in shade than canopy topographic-restricted species for stomatal conductance, specific leaf area, and thicknesses of leaf blade, palisade layer and upper epidermal layer. 
Most shade tolerant species exhibited better growth under partial-shade and partial sun-than full-sun and deep-shade. The inter-relationships documented in this study, revealed a strong correlation exists between root mass ratio and leaf mass ratio, and between total dry mass and root collar diameter in canopy, understorey, canopy topographic-restricted and canopy topographic-generalist species. Canopy species showed strong correlation between specific leaf area and palisade layer thickness.

Results from this study provide the ability to rank shade tolerance of each species. 